\title{
Research on cadmium adsorption-desorption dynamics of biochars
}

\author{
Zhenyu Zhang ${ }^{1,2}$, Shu Dang ${ }^{2 *}$,Guiping Zheng ${ }^{1}$, Haibo Li $^{2}$ \\ ${ }^{1}$ Heilongjiang Bayi Agricultural University, Daqing, 163000, China \\ ${ }^{2}$ Jilin Agricultural Science and Technology University, Jilin, 132101, China \\ *Corresponding author: Dr Shu Dang(Tel:+008613596353570;E-mail:dangshu1983@163.com)
}

\begin{abstract}
Biochar has high potential usage in retaining various contaminants, wastewater treatment, and water purification. In this study, three rice husk derived biochars with pyrolysis temperature 300,400 and $500{ }^{\circ} \mathrm{C}$, respectively, and pristine rice rusk were used to remove cadmium from aqueous solution. The results showed that about $70 \%$ or more of $\mathrm{Cd}^{2+}$ adsorption occurred in the first 960 mins of adsorption kinetics. The $\mathrm{Cd}^{2+}$ adsorption capacity under equilibrium increased with increasing pyrolysis temperature, probably attributed to the increased specific surface area (SSA) under higher pyrolysis temperature noting that significant linear correlation occurred between $\mathrm{Cd}^{2+}$ adsorption capacity and SSA. The $\mathrm{Cd}^{2+}$ adsorption could be best fitted by pseudo-second order model relative to Elovich model and pseudo-first order model. The $\mathrm{Cd}^{2+}$ adsorption rates were higher in film diffusion stage, indicating that film diffusion stage was significant and fast in the early stage of $\mathrm{Cd}^{2+}$ adsorption. In contrast, $\mathrm{Cd}^{2+}$ adsorption by intra-particle diffusion accounted for $47.0 \%, 47.9 \%$ and $43.9 \%$ on average of the total $\mathrm{Cd}^{2+}$ adsorption, respectively, indicating that intra-particle diffusion of $\mathrm{Cd}^{2+}$ played a more predominant role in limiting $\mathrm{Cd}^{2+}$ adsorption rate. When reaching $\mathrm{Cd}^{2+}$ desorption equilibrium, removal ratio $(\mathrm{RR})$ values were averaged $0.96,0.91$, and 0.90 under three initial concentrations. More than 90 percentage on average of $\mathrm{Cd}^{2+}$ was removed from aqueous solution by biochars and rice rusk as well, thus biochars can be used to efficiently remove contaminants from aqueous environment. Cation exchange, electrostatic attraction, and the complexation with surface functional groups could be the main dominant mechanisms for $\mathrm{Cd}^{2+}$ adsorption-desorption on biochars.
\end{abstract}

Keywords Biochar; Cadmium; Pyrolysis temperature; Adsorption kinetics; Desorption 


\section{Introduction}

Biochar has attracted global attention due to its high potential usage over the last decades such as wastewater treatment, water purification, retaining various contaminants, $\mathrm{CO}_{2}$ capture, and soil amelioration to improve soil fertility and carbon sequestration, etc. (Ahmad et al. 2014; Leng et al. 2015; Tan et al. 2016; Oliveira et al. 2017; Hossain et al. 2020). Biochar is a carbon-rich material derived from a wide range of biomass or organic waste through the thermochemical route (Porpatham et al., 2012), and holds distinctive properties such as high carbon content, larger porosity, greater specific surface area (SSA), cation exchange capacity (CEC) and nutrient retention capacity, and stable structure (Sakhiya et al. 2020). Recent studies in literature showed that biochars had been used to remove organic contaminants such as insecticides (imidacloprid and clothianidin) from soils (Zhang et al. 2021), and herbicide (atrazine) and PAH (Phenanthrene) (Yang et al., 2020; Lian et al. 2019) from aqueous solution. Biochar shows strong alkalinity and is negatively charged in the surface, thereby can interact with metallic ions through ion exchange, electrostatic attraction (Jiang et al. 2012), and surface complexation with oxygen functional groups, precipitation, and metal- $\pi$ electron interaction, in recent studies (Hossain et al. 2020).

Cadmium $(\mathrm{Cd})$ is one kind of heavy metals that any organisms do not need due to its strong harmful effects on biochemical and physiological processes (Matei et al. 2015; Naushad et al. 2015). Cadmium, generally in the form of ions $\left(\mathrm{Cd}^{2+}\right)$, was exposed in soil or aqueous environments through accumulation of garbage, sewage 
irrigation and improper fertilization (Zhu et al. 2017). Cadmium showed very big mobility in soil-plant continuum, and did not leach with water easily (Bolan et al. 2014). Cadmium pollution has become a global environmental problem in recent years and show great potential harm to human body.

The Cd adsorption in soils could influence the mobilization, transformation and bioaccumulation of $\mathrm{Cd}$, and decrease the bioavailability and environmental risks (Khan et al. 2018). Biochar containing functional groups can effectively reduce the effect of $\mathrm{Cd}$ stress by intensifying the adsorption of $\mathrm{Cd}$ in the soil, thereby significantly reducing the $\mathrm{Cd}$ content in plant (tobacco), and providing a theoretical basis and method to alleviate soil Cd pollution and enhance soil remediation (Ren et al. 2021). Biochar applied as an environmental friendly amendment in Cd-polluted soil could ameliorate the negative influences of $\mathrm{Cd}$ stress on plant (Khan et al. 2020b). and reduces Cd levels in the plant leaves due to the absorption properties of biochar, therefore the usage of biochar in contaminated soil could help reduce pollutions and decreases the human risk assessment (Mehdizadeh et al. 2021). Biochar could remove $\mathrm{Cd}$ from aqueous environment, e.g., $\mathrm{MgCl}_{2}$ modified biochar had much higher $\mathrm{Cd}(\mathrm{II})$ adsorption of capability than that of pristine biochar due to its enhanced ion exchange ability (Zhang et al., 2021), and the $\mathrm{H}_{3} \mathrm{PO}_{4}$ modified biochar significantly increased the removal rate of $\mathrm{Cd}(\mathrm{II})$ from water ( $\mathrm{Li}$ et al. 2020). In addition, (Khan et al. 2020a) presented a novel adsorbent with biochar modified with iron and $\mathrm{MoS}_{2}$ which had higher surface area and stronger adsorption capability for $\mathrm{Cd}$ from aqueous solution than the unmodified biochar. The similar results had been 
achieved by (Zhu et al. 2020), who showed that the adsorption capacity of surface aminated biochar and surface oxidized biochar for Cd was 23.54 and $19.04 \mathrm{mg} \mathrm{g}^{-1}$, respectively, which was about three times higher than that of the pristine porous biochar. Much more researches including those described above indicated that biochars (both modified and unmodified) hold stronger adsorption ability for $\mathrm{Cd}$, however, the adsorption-desorption dynamics, factors such as pyrolysis temperature, specific surface area (SSA) related to adsorption capacity, and sorption mechanisms need further study.

The present research was aimed to compare adsorption-desorption kinetic behavior of biochar obtained under three pyrolysis temperatures, examine the diversity for adsorption-desorption kinetics characteristics, and explores the adsorption mechanisms and more suitable ways to reduce the effectiveness of heavy metals such as cadmium.

\section{Materials and methods}

\subsection{Materials}

Biochar was made from rice husks. After drying at room temperature, rice husks were taken into the muffle furnace (Fisher Scientific, USA). At 3 different pyrolysis temperature $\left(300^{\circ} \mathrm{C}, 400^{\circ} \mathrm{C}, 500^{\circ} \mathrm{C}\right)$, with residences time for 30 minutes, then carbonization process was completed.

The chemical reagent $\mathrm{Cd}\left(\mathrm{NO}_{3}\right)_{2} \cdot 4 \mathrm{H}_{2} \mathrm{O}$ (analytical grade) was resolved in a solution of $0.005 \mathrm{~mol} \mathrm{~L}^{-1} \mathrm{CaCl}_{2} \cdot 2 \mathrm{H}_{2} \mathrm{O}$, the initial $\mathrm{Cd}^{2+}$ concentrations were $0.5,2.5$ 
and $5 \mathrm{mg} \mathrm{L}^{-1}$, respectively. The solution $\mathrm{pH}$ was adjusted to 6 using $0.1 \mathrm{~mol} \mathrm{~L}^{-1}$ $\mathrm{NaOH}$ or $\mathrm{HCl}$ solution.

\subsection{Determination of biochar characters}

Using $0.3 \mathrm{~g}$ biochar sample, the specific surface area (SSA) was measured by SSA and pore size analyzer (V-sorp4800b, Beijing, China). The energy spectrum analysis of biochar was measured by energy disperse spectroscopy (QUANTAX 50, Germany).

\subsection{Adsorption kinetics}

Firstly, $0.3 \mathrm{~g}$ rice husk and biochar samples under three pyrolysis temperatures were put respectively into $100 \mathrm{ml}$ centrifuge tube containing $0.005 \mathrm{~mol} \mathrm{~L}^{-1}$ $\mathrm{CaCl}_{2} \cdot 2 \mathrm{H}_{2} \mathrm{O}$ solution with the initial $\mathrm{Cd}^{2+}$ concentrations as $0.5,2.5$ and $5 \mathrm{mg} \mathrm{L}^{-1}$, respectively, shaken at stable temperature environment of $25^{\circ} \mathrm{C}$, and taken out after 5min, 15min, 30min, 60min, 120min, 240min, 480min, 960min, 1920min, 3840min and 7680min, respectively. Three $\mathrm{ml}$ supernatant liquid was taken out each time, right after 20 min's (4000 r/min) centrifuge. Atomic absorption spectrophotometer (AA-7000, Japan) was used to measure $\mathrm{Cd}^{2+}$ concentration. After the adsorption kinetics experiment finished, $25 \mathrm{ml} 0.01 \mathrm{~mol} / \mathrm{L} \mathrm{Ca}\left(\mathrm{NO}_{3}\right)_{2}$ solution was added into centrifuge tube which contained rice husk and biochar samples with adsorbed $\mathrm{Cd}^{2+}$. and shaken under $25^{\circ} \mathrm{C}$ and took them out in $5 \mathrm{~min}, 15 \mathrm{~min}, 30 \mathrm{~min}, 60 \mathrm{~min}, 120 \mathrm{~min}$, 240min, 480min, 960min, 1920min, 3840min and 7680min, respectively. the samples were centrifuged for $20 \mathrm{~min}(4000 \mathrm{r} / \mathrm{min})$ and poured out the supernatant fluid for 
$\mathrm{Cd}^{2+}$ concentration determination. Then, $25 \mathrm{ml} 0.01 \mathrm{~mol} / \mathrm{L} \mathrm{Ca}\left(\mathrm{NO}_{3}\right)_{2}$ was put in centrifuge tube one more time to start another desorption cycle.

\subsection{Data analysis}

Three adsorption kinetics models were used to account for $\mathrm{Cd}^{2+}$ adsorption kinetics.

The pseudo-first order model was expressed as:

$$
\ln \left(q_{e}-q_{t}\right)=\ln q_{e}-k_{1} t
$$

The pseudo-second order model was expressed as:

$$
\frac{t}{q_{t}}=\frac{1}{k_{2} q_{e}^{2}}+\frac{1}{q_{e}} t
$$

where $k_{1}$ is the first order rate constant $\left(\mathrm{h}^{-1}\right), k_{2}$ is the pseudo second-order rate constant $\left(\mathrm{g} \mathrm{mg}^{-1} \mathrm{~h}^{-1}\right), q_{e}\left(\mathrm{mg} \mathrm{g}^{-1}\right)$ and $q_{t}\left(\mathrm{mg} \mathrm{g}^{-1}\right)$ are the amounts of CIP adsorbed at equilibrium and at time $t$, respectively. The slope from the plot of $\ln \left(q_{e}-q_{t}\right)$ vs. $t$ indicates the value of $k_{1}$, and $k_{2}$ and $q_{e}$ values were calculated from the slope and intercept of the $t / q_{t}$ vs. $t$ plot. $t$ is the contact time (min).

The simplified Elovich model equation was expressed as:

$$
q_{t}=\beta \ln (\alpha \beta)+\beta \ln t
$$

where the constants $\alpha$ and $\beta$ are obtained from the slope and intercept of the linear plot of $q_{t}$ vs. $\ln t$.

The Weber-Morris intra-particle diffusion model equation was expressed as:

$$
q_{t}=k_{i} t^{1 / 2}+C_{i}
$$

where $k_{\mathrm{i}}$ is the intra-particle diffusion rate constant $\left(\mathrm{mg} \mathrm{g}^{-1} \mathrm{~h}^{-1 / 2}\right)$ and $C_{\mathrm{i}}$ is a constant that indicates the thickness of the boundary layer. 
The extent of desorption was described by removal ratio (RR) referring to Li et al. (2018) and modified, was calculated as:

$$
R R=\left(q_{a d s}-q_{d e s}\right) / q_{a d s}
$$

where $q_{a d s}$ and $q_{\text {des }}\left(\mathrm{mg} \mathrm{kg}^{-1}\right)$ represent the solid-phase concentrations $\mathrm{Cd}^{2+}$ adsorption and $\mathrm{Cd}^{2+}$ desorption, respectively.

The statistical analysis was conducted by SPSS 16.0. One-way analysis of variance (ANOVA; F-test) was conducted to compare the difference among treatments. A Pearson's bivariate linear correlation test was used for detecting the relationship among variables of interest.

\section{Results and discussion}

\subsection{Specific surface area}

The specific surface area (SSA) of biochars tended to increase linearly with the increase in pyrolysis temperatures (Table 1$)(\mathrm{r}=0.841, P=0.159)$. The significant differences $(P<0.05)$ in SSA were observed between higher temperature pyrolysed biochars, i.e., T-400 and T-500, and rice husks (T-0). The SSA of biochars with pyrolysis temperature $300{ }^{\circ} \mathrm{C}$ (T-300) increased by $26.5 \%$ as compared with rice husks (T-0), while the SSA of biochars with pyrolysis temperature $400{ }^{\circ} \mathrm{C}(\mathrm{T}-400)$ and $500{ }^{\circ} \mathrm{C}(\mathrm{T}-500)$ increased by 3.7 and 4.8 times as compared with rice husks (T-0). The high operational temperature during pyrolysis enhanced the surface area of biochar (Nguyen et al. 2010). The increase in SSA could enhance the adsorption 
capacity of contaminants onto adsorbents ( $\mathrm{Li}$ et al. 2014). In addition, the properties of biochar such as $\mathrm{C}$ content, $\mathrm{C} / \mathrm{H}$ ratio, and the degree of aromatization increased with increasing pyrolysis temperature (Zhou et al. 2017), which may help increase the adsorption ability of biochar.

\subsection{Adsorption kinetics modeling}

The contact time is regarded as one of the important factors affecting the adsorption process ( $\mathrm{Li}$ et al. 2018). Fig. 2 shows the dynamic adsorption process of $\mathrm{Cd}^{2+}$ onto rice husks (T-0) and biochars (T-300, T400, and T-500) under different initial $\mathrm{Cd}^{2+}$ concentrations. For biochar $\mathrm{T}-500$ under 0.5 and $2.5 \mathrm{mg} \mathrm{L}^{-1}$ initial concentration, a sharp increase ( $>$ or $\approx 80 \%)$ in $\mathrm{Cd}^{2+}$ adsorption took place within the first 240 mins (Fig.2 A, A1), which ran faster than rice husks and biochar T-300 and T-400. More than $90 \% \mathrm{Cd}^{2+}$ adsorption onto biochar T-500 occurred within the first 480 mins under $0.5 \mathrm{mg} \mathrm{L}^{-1}$ initial concentration, however, this event lagged behind under 2.5 and $5 \mathrm{mg} \mathrm{L}^{-1}$ initial concentration relative to that under $0.5 \mathrm{mg} \mathrm{L}^{-1}$ initial concentration. Within the first 960 mins $\mathrm{Cd}^{2+}$ adsorption onto the adsorbents accounted for $79.3 \%$ on average (61-95\%) of the total $\mathrm{Cd}^{2+}$ removal under $0.5 \mathrm{mg} \mathrm{L}^{-1}$ initial concentration (Fig.2 A1). Similarly, $73.7 \%$ on average (63-89\%) and $69.7 \%$ on average (65-79\%) of $\mathrm{Cd}^{2+}$ removal occurred within the first 960 mins under 2.5 and 5 $\mathrm{mg} \mathrm{L}^{-1}$ initial concentration, respectively (Fig.2 B1, C1). This linear phase may be related to the time needed to saturate the external surface of the carbonaceous agglomerates (Ncibi and Sillanpää, 2015), and thereafter a transition phase was observed as the adsorption rate began to decrease attributable to the slow diffusion of 
contaminants within the porous structure (960-7680 mins) (Li et al., 2018). Finally, the $\mathrm{Cd}^{2+}$ adsorption dynamic curve leveled off. $\mathrm{The} \mathrm{Cd}^{2+}$ adsorption capacity under equilibrium increased with increasing pyrolysis temperature, which may be attributed to the increased SSA under higher pyrolysis temperature. A linear relationship was observed between $\mathrm{Cd}^{2+}$ adsorption capacity and SSA $(\mathrm{r}=0.958, P=0.042$, under 0.5 $\mathrm{mg} \mathrm{L} \mathrm{L}^{-1}$ initial concentration; $\mathrm{r}=0.997, P=0.003$, under $2.5 \mathrm{mg} \mathrm{\textrm {L } ^ { - 1 }}$ initial concentration; $\mathrm{r}=0.936, P=0.064$, under $5 \mathrm{mg} \mathrm{L}^{-1}$ initial concentration).

The adsorption kinetics could be fitted resorting to Lagergren pseudo-first order, pseudo-second order, and Elovich models in terms of their wide use (Konggidinata et al., 2017; Li et al., 2018). The calculated kinetic parameters for pseudo-first order (PFO), pseudo-second order (PSO), and Elovich models are shown in Table 2. For pseudo-first order model, no significant difference in the calculated rate constants of $k_{1}$ was found both under different temperatures and initial $\mathrm{Cd}^{2+}$ concentrations. In contrast, for pseudo-second order model the calculated rate constants of $k_{2}$ tended to decrease when the initial $\mathrm{Cd}^{2+}$ concentration increase from 0.5 to $5 \mathrm{mg} \mathrm{L}^{-1}$ for all adsorbents, indicating that $\mathrm{Cd}^{2+}$ removal efficiency depended on $\mathrm{Cd}^{2+}$ concentration within an aqueous environment, the $\mathrm{Cd}^{2+}$ removal was a slower process within higher $\mathrm{Cd}^{2+}$ concentration solution.

The $\mathrm{Cd}^{2+}$ adsorption could be best fitted by pseudo-second order rather than Elovich model and pseudo-first order model as shown by higher $r^{2}$ values (Table 2). The similar results were obtained by recent studies (Park et al., 2019; Penido et al., 2019; Khan et al. 2020a). The pseudo-second order model generally assumes that the 
rate limiting step during the adsorption process is a chemical adsorption ( $\mathrm{Li}$ et al. 2015b).

\subsection{Rate controlling step analysis}

The Weber-Morris intra-particle diffusion model suggested that film diffusion or intra-particle diffusion was a rate limiting step (Bedin et al., 2016; Konggidinata et al. 2017). Fig. 3 showed that the plots of $\mathrm{Cd}^{2+}$ adsorption on rice husks and three biochars against $\mathrm{t}^{0.5}$ under different $\mathrm{Cd}^{2+}$ initial concentration were not straight lines which did not pass through the origin, indicating that intra-particle diffusion was not the sole rate-limiting step and more than one mechanism should account for the $\mathrm{Cd}^{2+}$ adsorption (Li et al. 2018) studied ciprofloxacin adsorption onto carbon nanotubes, and showed three stages of ciprofloxacin adsorption process in which film diffusion (external mass transfer) and intra-particle diffusion were distinct. In addition, (Parket al. 2019) suggested that the adsorption of Cd by pine tree residue biochars (PRBs) could be divided into two stages: rapid adsorption on the initial boundary layer and slow adsorption by intraparticle diffusion. The present study showed that $\mathrm{Cd}^{2+}$ adsorption rate (line slope in Fig. 4) of three stages decreased in the order: film diffusion $>$ intraparticle diffusion $>$ adsorption onto the active sites, significantly for $\mathrm{Cd}^{2+}$ adsorption within 2.5 and $5 \mathrm{mg} \mathrm{L}^{-1}$ solution, indicating that film diffusion stage was significant and fast (within one hour) in the early stage of $\mathrm{Cd}^{2+}$ adsorption ( $\mathrm{Li}$ et al., 2018). In this stage, $\mathrm{Cd}^{2+}$ adsorption accounted for $32.3,25.8$ and $25.8 \%$ on average of the total $\mathrm{Cd}^{2+}$ adsorption onto all adsorbents within $0.5,2.5$ and $5 \mathrm{mg} \mathrm{L}^{-1}$ solution, respectively. In contrast, $\mathrm{Cd}^{2+}$ adsorption by intra-particle diffusion 
accounted for $47.0 \%, 47.9 \%$ and $43.9 \%$ on average of the total $\mathrm{Cd}^{2+}$ adsorption, respectively, indicating that intra-particle diffusion of $\mathrm{Cd}^{2+}$ adsorption played a more predominant role in limiting $\mathrm{Cd}^{2+}$ adsorption rate on rice rusk and biochars. Similarly, Zhuindicated that physicochemical adsorption and intraparticle diffusion dominated the $\mathrm{Cd}$ adsorption(Zhu et al. 2020), and surface functional groups were identified as key factors controlling adsorption. In the present research, the film and intra-particle diffusions could be limiting factors controlling $\mathrm{Cd}^{2+}$ adsorption rate, particularly for three biochars.

\subsection{Desorption kinetics}

Desorption kinetics of $\mathrm{Cd}^{2+}$ from rice husks and biochars are depicted in Fig. 5. For $0.5 \mathrm{mg} \mathrm{L}^{-1}$ initial $\mathrm{Cd}^{2+}$ concentration, $\mathrm{Cd}^{2+}$ desorption quickly reached equilibrium, 120 mins for rice husks, 60 mins for biochar T-300 and T-400, and 15 mins for biochar T-500. For $2.5 \mathrm{mg} \mathrm{L}^{-1}$ initial $\mathrm{Cd}^{2+}$ concentration, $\mathrm{Cd}^{2+}$ desorption reached equilibrium at 120 mins for rice husks, 60 mins for biochar T-300, and 1920 mins for biochar $\mathrm{T}-400$ and $\mathrm{T}-500$. For $5 \mathrm{mg} \mathrm{L}^{-1}$ initial $\mathrm{Cd}^{2+}$ concentration, $\mathrm{Cd}^{2+}$ desorption reached equilibrium at 30 mins for rice husks and biochar T-300, and 1920 mins for biochar T-400 and T-500.

Fig. 6 shows the removal ratio (RR) of $\mathrm{Cd}^{2+}$ on rice husks and biochars from aqueous solution. The RR stands for the $\mathrm{Cd}^{2+}$ fixation on adsorbents after desorption cycles. When the $\mathrm{Cd}^{2+}$ desorption equilibrium was reached, $\mathrm{RR}$ values were averaged $0.96(0.93-0.98)$ for $0.5 \mathrm{mg} \mathrm{L}^{-1}$ initial concentration, $0.91(0.85-0.96)$ for $2.5 \mathrm{mg} \mathrm{L}^{-1}$ 
initial concentration, and $0.90(0.85-0.94)$ for $5 \mathrm{mg} \mathrm{L}^{-1}$ initial concentration. This indicated that more than 90 percentage of $\mathrm{Cd}^{2+}$ was removed from aqueous solution by rice rusk and biochars.

\subsection{Sorption mechanisms}

The present study indicated the biochars tested are strong and efficient adsorbents for $\mathrm{Cd}^{2+}$ removal from water solutions. The adsorption mechanisms include ion exchange, complexation, and electrostatic attraction, etc. Khan suggested that the adsorption process of $\mathrm{Cd}$ onto a surfaced modified biochar involved several mechanisms such as the complexation of $\mathrm{Cd}(\mathrm{II})$ with oxygen-based functional groups(Khan et al., 2020a), ion exchange, electrostatic attraction, $\mathrm{Cd}(\mathrm{II})-\pi$ interactions, metal-sulfur complexation, and inner-surface complexation. The interaction between carboxyl group and $\mathrm{Cd}$ dominated the adsorption performance of a surface oxidized biochar (OPBC), while the $\mathrm{Cd}^{2+}-\pi$ interaction was weakened by increasing the $\pi$ electron electrostatic potential of aromatic rings, Zhu showed in a recent research, and the lone pair electrons of the amino groups dominated the complexation of a surface aminated biochar (APBC) with $\mathrm{Cd}$, and the $\pi$ electron electrostatic potential was almost unaffected(Zhu et al. 2020). Park et al. (2019) demonstrated that the $\mathrm{Cd}$ adsorption on mixed pine tree residue biochars (M-PRB) was associated with functional groups such as $\mathrm{C}=\mathrm{C}, \mathrm{COH}$ and $\mathrm{COOH}$, as shown by FTIR, and the exchangeable cations corresponds to $23.6 \%$ of the total adsorption amount. Zhang et al. (2019) indicated the $\mathrm{Cd}^{2+}$ adsorption on a rice straw-derived biochar was mainly the complexation between $-\mathrm{NH}_{2}$ group on biochar surface and in 
solution. Zhou et al. (2018) suggested that the cation- $\pi$ interaction could act as the main mechanisms for $\mathrm{Cd}^{2+}$ adsorption on the biochar derived from tobacco stem at $700{ }^{\circ} \mathrm{C}$ for the residence time of $4-6 \mathrm{~h}$. Chen et al. (2019) showed that electrostatic interaction, precipitation, and $\mathrm{O}-\mathrm{H}$ bonds were the primary adsorption mechanisms for $\mathrm{Cd}^{2+}$ on a $\mathrm{H}_{3} \mathrm{PO}_{4}$-modified biochar prepared using chicken feather. However, cation exchange and precipitation were considered as the dominant adsorption mechanisms of $\mathrm{Cd}^{2+}$ on rice straw biochars prepared at $400{ }^{\circ} \mathrm{C}$ and $700{ }^{\circ} \mathrm{C}$, for $\mathrm{Cd}^{2+}$ and $\mathrm{Ni}^{2+}$ adsorption in the binary system (Deng et al. 2019). Chen et al. (2015) concluded that the main mechanism of the adsorption process of biochar derived from municipal sewage sludge for $\mathrm{Cd}^{2+}$ involves (1) surface precipitation by forming insoluble $\mathrm{Cd}^{2+}$ compounds in alkaline condition, and (2) ion exchange for $\mathrm{Cd}^{2+}$ with exchangeable cations in the biochar, such as $\mathrm{Ca}^{2+}$. Microstructure characteristics and mechanism analysis further suggested that coprecipitation and surface complexation were the main mechanisms of Cd adsorption by pinecone biochar (Teng et al. 2020). In brief, cation exchange, electrostatic attraction, the complexation of $\mathrm{Cd}^{2+}$ with functional groups, surface precipitation, and $\mathrm{Cd}^{2+}-\pi$ interaction, etc., can account for the cadmium adsorption-desorption mechanisms on biochars derived from different sources.

\section{Conclusions}

The specific surface area (SSA) of biochars tended to increase linearly with the increase in pyrolysis temperatures. The significant differences $(P<0.05)$ in SSA were observed among the adsorbents tested. About $70 \%$ or more of $\mathrm{Cd}^{2+}$ adsorption 
occurred in the first 960 mins. The $\mathrm{Cd}^{2+}$ adsorption capacity under equilibrium increased with increasing pyrolysis temperature, attributable to the increased SSA under higher pyrolysis temperature. Significant linear correlation was observed between $\mathrm{Cd}^{2+}$ adsorption capacity and SSA. The $\mathrm{Cd}^{2+}$ adsorption could be best fitted by pseudo-second order model relative to Elovich model and pseudo-first order model. The $\mathrm{Cd}^{2+}$ adsorption rate (line slope) defined by linear correlation in three stages decreased in the order: film diffusion $>$ intraparticle diffusion $>$ adsorption onto the active sites, significantly for $\mathrm{Cd}^{2+}$ adsorption within 2.5 and $5 \mathrm{mg} \mathrm{L}^{-1}$ solution, indicating that film diffusion stage was significant and fast (within one hour) in the early stage of $\mathrm{Cd}^{2+}$ adsorption. The $\mathrm{Cd}^{2+}$ adsorption by intra-particle diffusion accounted for more than $40 \%$ on average of the total $\mathrm{Cd}^{2+}$ adsorption, indicating that intra-particle diffusion of $\mathrm{Cd}^{2+}$ adsorption played a more predominant role in limiting $\mathrm{Cd}^{2+}$ adsorption rate. When reaching $\mathrm{Cd}^{2+}$ desorption equilibrium, removal ratio values were averaged more than 0.90 under three initial concentrations. More than 90 percentage on average of $\mathrm{Cd}^{2+}$ was removed from aqueous solution by biochars and rice rusk as well, thus biochars can be used to efficiently remove contaminants such as $\mathrm{Cd}^{2+}$ from aqueous environment. Cation exchange, electrostatic attraction, the complexation of $\mathrm{Cd}^{2+}$ with functional groups, surface precipitation, and $\mathrm{Cd}^{2+}-\pi$ interaction are the dominant mechanisms for $\mathrm{Cd}^{2+}$ adsorption-desorption on biochars.

Funding This work was supported by grants from Doctorate Foundation program from JLASTU,China (No 20185006). 
Data availability All data generated or analyzed during this study are included in this article.

\section{Compliance with ethical standards}

Conflict of interest The authors declare that they have no confict of interest.

Ethics approval and consent to participate Not applicable.

Consent for publication Not applicable.

\section{Authors Contributions}

Data curation: Zhenyu Zhang.

Funding acquisition:Guiping Zheng.Zhenyu Zhang.

Investigation: Shu Dang.

Methodology: Zhenyu Zhang, Haibo Li, Shu Dang.

Software: Zhenyu Zhang, Shu Dang.

Validation: Haibo Li, Guiping Zheng.

Writing - original draft:Zhenyu Zhang.

\section{References}

Ahmad Z, Gao B, Mosa A, Yu H, Yin X,Bashir A, Wang S (2018) Removal 
of $\mathrm{Cu}(\mathrm{II}), \mathrm{Cd}(\mathrm{II})$ and $\mathrm{Pb}$ (II) ions from aqueous solutions by biochars derived

frompotassium-rich biomass. Journal of Cleaner Production 180:437-449

Bedin K C, Martins A C, Cazetta A L, Pezoti O, Almeida V C (2016) KOH-

Activated carbon prepared from sucrose spherical carbon: adsorption equilibrium, kinetic and thermodynamic studies for Methylene Blue removal. Chemical

Engineering Journal 286:476-484

Bolan N, Kunhikrishnan A, Thangarajan R, Kumpiene J, Park J, BethKirkham

T, Scheckel K (2014) Remediation of heavy metal(loid)s contaminated soils to

mobilize or to immobilize. Journal of Hazardous Materials 266:141-166

Chen H, Gao B, Li H (2015) Removal of sulfamethoxazole and ciprofloxacin

from aqueous solutions by graphene oxide. Journal of Hazardous Materials

$282: 201-207$

Chen $\mathrm{H}$ Y, Li W Y, Wang J J, Xu H J, Liu Y L, Zhang Z, Li Y T, Zhang Y

L (2019) Adsorption of cadmium and lead ions by phosphoric acid-modified

biochar generated from chicken feather: Selective adsorption and influence of

Dissolved organic matter. Bioresource Technology 292:121948

Chen T, Zhou Z Y, Han R, Meng R H, Wang H T, Lu W J (2015) Adsorption 
of cadmium by biochar derived from municipal sewage sludge: Impact factors and adsorption mechanism. Chemosphere 134:286-293

Deng Y Y, Huang S, Laird D A, Wang X G, Men Z W (2019) Adsorption behaviour and mechanisms of cadmium and nickel on rice straw biochars in single-and binary-metal systems. Chemosphere 218:308-318

Drweesh S A, Fathy N A, Wahba M A, Hanna A A, Akarish A I M, Elzahan $\mathrm{y}$

E A M (2016) Equilibrium,kinetic and thermodynamic studies of $\mathrm{Pb}(\mathrm{II})$ adsorpt on from aqueous solutions on HCl-treated Egyptian kaolin. Journal of Environmental Chemical Engineering 4:674-1684

Hossain M Z , Bahar M M , Sarkar B, Donne S W, Ok Y S, Palansooriya K N, Kirkham M B, Chowdhury S, Bolan N (2020) Biochar and its importance on nutrient dynamics in soil and plant. Biochar 2:379-420

Jiang J , Xu R K, Jiang T Y, Li Z (2012) Immobilization of $\mathrm{Cu}(\mathrm{II}), \mathrm{Pb}(\mathrm{II})$ and Cd(II) by the addition of rice straw derived biochar to a simulated polluted Ultisol. Journal of Hazardous Materials 229:145-150

Khan M A, Ding X, Khan S, Brusseau M L, Khan A, Nawab J (2018) The influence of various organic amendments on the bioavailability and plant 
uptake of cadmium present in mine-degraded soil. Science of Total

Environment $636: 810-817$

Khan Z H, Gao M L, Qiu W W, ShafiqulIslam M, Song Z G (2020)

Mechanisms for cadmium adsorption by magnetic biochar composites in an aqueous solution. Chemosphere 246:125701

Khan Z H, Gao M L, Qiu W W, Song Z G (2020) Properties and adsorption mechanism of magnetic biochar modified with molybdenum disulfide for cadmi umin aqueous solution. Chemosphere 255:126995

Konggidinata M I, Chao B, Lian Q Y, Subramaniam R, Zappi M, Gang D D (2017) Equilibrium,kinetic and thermodynamic studies for adsorption of BTEX onto Ordered Mesoporous Carbon (OMC). Journal of Hazard.Mater 336:249-259

Lei S C, Zhu L, Xu C, Hong C Y, Wang J L, Che L, Hu Y F, Qiu Y P (2020) Mechanistic insights and multiple characterizations of cadmium binding To animal-derived biochar. Environmental Pollution 258:113675 Leng L, Yuan X, Huang H, Shao J, Wang H (2015) Applied Surface Science Biochar derived from sewage sludge by liquefaction:characterization and application for dye adsorption. Appl Surface Science 346,223-231.

Li H B, Zhang D, Han X Z, Xing B (2014) Adsorption of antibiotic 
ciprofloxacin on carbon nanotubes:pH dependence and thermodynamics.

Chemosphere 95:150-155

Li H B, Wu W H, Hao X X, Wang S, You M Y, Han X Z, Xing B (2018)

Removal of ciprofloxacin from aqueous solutions by ionic surfactant-modified

carbon nanotubes. Environmental Pollution 243:206-217

Li X N, Chen S, Fan X F, Quan X, Tan F, Zhang Y B, Gao J S (2015)

Adsorption of ciprofloxacin,bisphenol and 2-chlorophenol on electrospun

carbon nanofibers:In comparison with powder activated carbon.J. Journal of

Colloid and Interface Science 447:120-127

Li X P, Wang C B, Tian J N, Liu J P, Chen G (2020) Comparison of

adsorption properties for cadmium removal from aqueous solution by Enteromor

phaprolifera biochar modified with different chemical reagents. Environmental

Research 186:109502

Lian F, Yu W H, Wang Z Y, Xing B (2019) New Insights into Black Carbon

Nanoparticle-induced Dispersibility of Goethite Colloids and Configuration-

dependent Sorption for Phenanthrene. Environmental Science \& Technology

$53,(2): 661-670$

Matei N, Popescu A, Radu G L (2015) Cadmium and lead occurrence in soil 
and grape from Murfatlar Vineyard. Ovidius University Annals of Chemistry $26(1): 37-40$

Mehdizadeh L, Farsaraei S, Moghaddam M (2021) Biochar application modifie growth and physiological parameters of Ocimum ciliatum L.and reduced human risk assessment under cadmium stress. Journal of Hazardous Materials 409:1249 54

Naushad M, Ahamad T, Alothman Z A (2015) Synthesis,characterization and application of curcumin formaldehyde resin for the removal of $\mathrm{Cd}^{2+}$ from wastewater:Kinetics,isotherms and thermodynamic studies. Journal of Industrial \& Engineering Chemistry 29:78-86

Ncibi M C, Sillanpää M (2015) Optimized removal of antibiotic drugs from aqueous solutions using single,double and multi-walled carbon nanotubes.

Journal of Hazardous Materials 298:102-110

Nguyen B, Lehmann J, Hockaday W C, Josep H S, Masiello C A (2010)

Temperature sensitivity of black carbon decomposition and oxidation.

Environmental science \& technology 44:3324-3331

Oliveira F R, Patel A K, Jaisi D P, Adhikari S, Lu H, Khanal S K (2010)

Environmental application of biochar:current status and perspectives. 
Bioresource Technology 246:110-122

Park J H, Wang J J, Kim S H, Kang S W, Jeong C Y, Jeon J R, Park K H,

Cho J S, Delaune R D, Seo D C (2019) Cadmium adsorption characteristics of biochars derived using various pine tree residues and pyrolysis temperatures.

Journal of Colloid and Interface Science 553:298-307

Penido E S, AzevedoMelo L C, Guilherme L R G, Lucia B M (2019)

Cadmium binding mechanisms and adsorption capacity by novel phosphorus magnesium-engineered biochars. Science of The Total Environment 671:

1134-1143

Porpatham E, Ramesh A, Nagalingam B (2012) Effect of compression ratio on the performance and combustion of a biogas fuelled spark ignition engine.

Fuel 95:247-256

Ren T B, Wan N C, Mahari A W, Xu C S, Feng H L, Ji X M, Yin Y, Chen P, Zhu S J, Liu H T, Liu G S, Li L T, Lam S S (2021) Biochar for cadmium pollution mitigation and stress resistance in tobacco growth.

Enviromental Research 192:110237

Sakhiya A K, Anand A, Kaushal P (2020) Production,activation,and application 
of biochar in recent times. Biochar 2:253-285

Tan X, Liu Y, Gu Y, Xu Y, Zeng G, Hu X (2016) Biochar-based nanocomposites for the decontamination of wastewater:a review. Bioresource Technology 212:318-333

Teixidó M, Hurtado C, Pignatello J J, Beltrán J L, Granados M,Peccia J (2013) Predicting contaminant adsorption in blackcarbon (biochar)-amended soil for the veterinary antimicrobial sulfamethazine. Environmental science \& Technology 47,(12):6197-6205

Teng D Y, Zhang B B, Xu G M, Wang B, Mao K, Wang J X, Sun J, Feng X B, Yang Z G , Zhang H (2013) Efficient removal of Cd(II) from aqueous solution by pinecone biochar:Sorption performance and governing mechanisms. Environmental Pollution 265:Part A,115001

Wang Y F , Kang J M, Jiang S M, Li H, Ren Z Y, Xu Q B, Jiang Q, Liu W Z, Li R Z, Zhang Y (2020) A composite of Ni-Fe-Zn layered double hydroxides/biochar for atrazine removal from aqueous solution. Biochar 2:455464

Wu J W, Wang T, Wang J W, Zhang Y S, Pan W P (2021) A novel modified 
method for the efficient removal of $\mathrm{Pb}$ and $\mathrm{Cd}$ from wastewater by biochar Enhanced the ion exchange and precipitation capacity. Science of The Total Environment 754:142150

Zhang D W, Zhang K J, Hu X L, He Q Q, Yan J P, Xue Y W (2019)

Cadmium removal by $\mathrm{MgCl}_{2}$ modified biochar derived form crayfish shell waste:batch adsorption,response surface analysis and fixed bed filtration. Journal Hazardous Materials 408,124860.

Zhang P, Min L J, Tang J C, Rafiq M K, Sun H W (2020) Sorption and degradation of imidacloprid and clothianidin in Chinese paddy soil and red soil amended with biochars. Biochar 2:329-341

Zhang,Y.P.,Yue,X.P.,Xu,W.W.,Zhang,H(2019)Y.Amino modification of rice straw-derived biochar for enhancing its cadmium (II) ions adsorption from water.Journal of Hazardous Materials 379:120783

Zhou Y X, Berruti F, Greenhalf C (2017) Increased retention of soil nitrogen over winter by biochar application:implications of biochar pyrolysis temperature for plant nitrogen availability .Agriculture,Ecosystems and Environment 236:

$61-68$

Zhou Z, Xu Z H, Feng Q J, Yao D H, Yu J G, Wang D S, Lv S Q, Liu Y 
F, Zhou N, Zhong M E (2018) Effect of pyrolysis condition on the adsorption mechanism of lead,cadmium and copper on tobacco stem biochar. Journal of Cleaner Production 187:996-1005

Zhu L, Tong L H, Zhao N, Wang X, Yang X X, Lv Y Z (2020) Key factors and Microscopic mechanisms controlling adsorption of cadmium by surface oxidized and aminated biochars. Journal of Hazardous Materials 382: 121002

Zhu W, Du W, Shen X (2017) Comparative adsorption of $\mathrm{Pb}^{2+}$ and $\mathrm{Cd}^{2+}$ by cow manure and its vermicompost. Environmental Pollution 227:89-97 


\section{Table and figure legends}

\section{Table 1}

Specific surface area (SSA) of rice husks (T-0) and biochars (T-300, T-400, T-500) under different pyrolysis temperature

\section{Table 2.}

Adsorption kinetics of $\mathrm{Cd}^{2+}$ onto rice husks (T-0) and biochars (T-300, T-400, T-500) with the initial concentrations as $0.5,2.5$, and $5 \mathrm{mg} / \mathrm{L}$, respectively.

\section{Table 3.}

The fitted Weber-Morris intra-particle diffusion model

Fig 1. Biochar produced at pyrolysis temperatures as 300,400 , and $500{ }^{\circ} \mathrm{C}$, respectively.

Fig. 2. Adsorption kinetics of $\mathrm{Cd}^{2+}$ on rice rusk (T-0) and biochars with pyrolysis temperatures as 300 (T-300), 400 (T-400), $500{ }^{\circ} \mathrm{C}$ (T-500), respectively. A, B, C represent adsorption kinetics of $\mathrm{Cd}^{2+}$ from beginning to 7680 mins, while $\mathrm{A} 1, \mathrm{~B} 1, \mathrm{C} 1$ represent adsorption kinetics of $\mathrm{Cd}^{2+}$ from beginning to 960 mins with initial concentrations as $0.5,2.5$, and $5 \mathrm{mg} \mathrm{L}^{-1}$, respectively.

Fig. 3. Adsorption kinetics of $\mathrm{Cd}^{2+}$ on rice rusk (T-0) and biochars with pyrolysis temperatures as $300(\mathrm{~T}-300), 400(\mathrm{~T}-400), 500{ }^{\circ} \mathrm{C}$ (T-500), respectively, depending upon $\mathrm{t}^{0.5}\left(\min ^{0.5}\right)$. A, B, C represent adsorption kinetics of $\mathrm{Cd}^{2+}$ with initial 
concentrations as $0.5,2.5$, and $5 \mathrm{mg} \mathrm{L}^{-1}$, respectively.

Fig. 4. Adsorption kinetics of $\mathrm{Cd}^{2+}$ on rice rusk (T-0) and biochars with pyrolysis temperatures as $300(\mathrm{~T}-300), 400(\mathrm{~T}-400), 500{ }^{\circ} \mathrm{C}$ (T-500), respectively, depending upon $\mathrm{t}^{0.5}\left(\min ^{0.5}\right)$. A, B, C represent adsorption kinetics of $\mathrm{Cd}^{2+}$ with initial concentrations as $0.5,2.5$, and $5 \mathrm{mg} \mathrm{L}^{-1}$, respectively. Correlation analysis between CIP adsorption and $\mathrm{t}^{0.5}\left(\mathrm{~h}^{0.5}\right)$ on the three stages, number 1, 2, and 3 represent stages of external mass transfer, intraparticle diffusion, and adsorption onto the active sites, respectively.

Fig. 5. Desorption kinetics of $\mathrm{Cd}^{2+}$ from rice rusk (T-0) and biochars with pyrolysis temperatures as 300 (T-300), 400 (T-400), $500{ }^{\circ} \mathrm{C}$ (T-500), respectively. A, B, C represent desorption of $\mathrm{Cd}^{2+}$ from beginning to 7680 mins, while $\mathrm{A} 1, \mathrm{~B} 1, \mathrm{C} 1$ represent desorption of $\mathrm{Cd}^{2+}$ from beginning to 120 mins for $0.5 \mathrm{mg} \mathrm{L}^{-1}$ initial concentration, and to $1920 \mathrm{mins}$ for 2.5 , and $5 \mathrm{mg} \mathrm{L}^{-1}$, respectively.

Fig. 6. Removal rate of $\mathrm{Cd}^{2+}$ on rice rusk (T-0) and biochars with pyrolysis temperatures as $300(\mathrm{~T}-300), 400(\mathrm{~T}-400), 500{ }^{\circ} \mathrm{C}(\mathrm{T}-500)$, respectively, from aqueous solution. A, B, C represent removal rate of $\mathrm{Cd}^{2+}$ from beginning to $7680 \mathrm{mins}$, while $\mathrm{A} 1, \mathrm{~B} 1, \mathrm{C} 1$ represent removal rate of $\mathrm{Cd}^{2+}$ from beginning to $120 \mathrm{mins}$ for $0.5 \mathrm{mg} \mathrm{L}^{-1}$ initial concentration, and to 960 mins with as 2.5 and $5 \mathrm{mg} \mathrm{L}^{-1}$, respectively. 
Table 1

Specific surface area (SSA) of rice husks (T-0) and biochars (T-300, T-400, T-500) under different pyrolysis temperature

\begin{tabular}{lllll}
\hline & $\mathrm{T}-0$ & $\mathrm{~T}-300$ & $\mathrm{~T}-400$ & $\mathrm{~T}-500$ \\
\hline Pyrolysis temperature $\left({ }^{\circ} \mathrm{C}\right)$ & 0 & 300 & 400 & 500 \\
BET Specific surface area & $9.17 \mathrm{c}$ & $11.60 \mathrm{c}$ & $52.42 \mathrm{~b}$ & $62.15 \mathrm{a}$ \\
Langmuir Specific surface area & $16.71 \mathrm{c}$ & $19.14 \mathrm{c}$ & $68.24 \mathrm{~b}$ & $83.51 \mathrm{a}$ \\
\hline
\end{tabular}


The means in the same row with small letters differ significantly in the different treatments $(P<0.05)$.

Table 2. 
Adsorption kinetics of $\mathrm{Cd}^{2+}$ onto rice husks (T-0) and biochars (T-300, T-400, T-500) with the initial concentrations as $0.5,2.5$, and $5 \mathrm{mg} / \mathrm{L}$, respectively.

\begin{tabular}{|c|c|c|c|c|c|}
\hline \multirow{2}{*}{$\begin{array}{l}\text { Initial concentration } \\
(\mathrm{mg} / \mathrm{L})\end{array}$} & \multirow{2}{*}{$\begin{array}{l}\text { pyrolysis } \\
\text { temperature } \\
\mathrm{S}\end{array}$} & \multicolumn{4}{|c|}{ Pseudo-first order kinetics } \\
\hline & & $q_{\mathrm{e}}$ & $k_{1}$ & $r^{2}{ }_{\text {adj }}$ & $P$-value \\
\hline \multirow[t]{4}{*}{0.5} & $\mathrm{~T}-0$ & 58.8 & 0.0011 & 0.9158 & $<0.0001$ \\
\hline & $\mathrm{T}-300$ & 66.7 & 0.0008 & 0.9613 & $<0.0001$ \\
\hline & $\mathrm{T}-400$ & 61.5 & 0.0013 & 0.9466 & $<0.0001$ \\
\hline & $\mathrm{T}-500$ & 28.8 & 0.0011 & 0.9020 & $<0.0001$ \\
\hline \multirow[t]{4}{*}{2.5} & $\mathrm{~T}-0$ & 275.1 & 0.0010 & 0.9402 & $<0.0001$ \\
\hline & $\mathrm{T}-300$ & 286.6 & 0.0011 & 0.9338 & $<0.0001$ \\
\hline & $\mathrm{T}-400$ & 305.0 & 0.0010 & 0.9510 & $<0.0001$ \\
\hline & $\mathrm{T}-500$ & 188.0 & 0.0011 & 0.9484 & $<0.0001$ \\
\hline \multirow[t]{6}{*}{5} & $\mathrm{~T}-0$ & 488.3 & 0.0011 & 0.9493 & $<0.0001$ \\
\hline & $\mathrm{T}-300$ & 503.4 & 0.0012 & 0.9646 & $<0.0001$ \\
\hline & $\mathrm{T}-400$ & 532.0 & 0.0009 & 0.9568 & $<0.0001$ \\
\hline & $\mathrm{T}-500$ & 510.8 & 0.0009 & 0.9668 & $<0.0001$ \\
\hline & & \multicolumn{4}{|c|}{ Pseudo-second order kinetics } \\
\hline & & $q_{\mathrm{e}}$ & $k_{2}\left(\times 10^{-5}\right)$ & $r^{2}$ adj & $P$-value \\
\hline \multirow[t]{4}{*}{0.5} & $\mathrm{~T}-0$ & 58.8 & 5.08 & 0.9956 & $<0.0001$ \\
\hline & $\mathrm{T}-300$ & 69.9 & 2.51 & 0.9861 & $<0.0001$ \\
\hline & $\mathrm{T}-400$ & 84.0 & 8.21 & 0.9997 & $<0.0001$ \\
\hline & $\mathrm{T}-500$ & 83.3 & 29.1 & 0.9999 & $<0.0001$ \\
\hline \multirow[t]{4}{*}{2.5} & $\mathrm{~T}-0$ & 285.7 & 0.498 & 0.9789 & $<0.0001$ \\
\hline & $\mathrm{T}-300$ & 285.7 & 0.854 & 0.9960 & $<0.0001$ \\
\hline & $\mathrm{T}-400$ & 370.4 & 0.800 & 0.9972 & $<0.0001$ \\
\hline & $\mathrm{T}-500$ & 384.6 & 1.37 & 0.9997 & $<0.0001$ \\
\hline 5 & $\mathrm{~T}-0$ & 526.3 & 0.602 & 0.9933 & $<0.0001$ \\
\hline
\end{tabular}




\begin{tabular}{|c|c|c|c|c|c|}
\hline & $\mathrm{T}-300$ & 555.6 & 0.392 & 0.9718 & $<0.0001$ \\
\hline & $\mathrm{T}-400$ & 625.0 & 0.352 & 0.9772 & $<0.0001$ \\
\hline & $\mathrm{T}-500$ & 714.3 & 0.537 & 0.9961 & $<0.0001$ \\
\hline & & \multicolumn{4}{|c|}{ Elovich model } \\
\hline & & $\alpha$ & $\beta$ & $r_{\text {adj }}^{2}$ & $P$-value \\
\hline \multirow[t]{4}{*}{0.5} & $\mathrm{~T}-0$ & 0.012 & 8.41 & 0.9316 & $<0.0001$ \\
\hline & $\mathrm{T}-300$ & 0.007 & 9.63 & 0.8827 & $<0.0001$ \\
\hline & $\mathrm{T}-400$ & 0.017 & 12.3 & 0.9632 & $<0.0001$ \\
\hline & $\mathrm{T}-500$ & 0.365 & 9.18 & 0.8914 & $<0.0001$ \\
\hline \multirow[t]{4}{*}{2.5} & $\mathrm{~T}-0$ & 0.002 & 40.0 & 0.9533 & $<0.0001$ \\
\hline & $\mathrm{T}-300$ & 0.002 & 41.3 & 0.9263 & $<0.0001$ \\
\hline & $\mathrm{T}-400$ & 0.002 & 53.8 & 0.9559 & $<0.0001$ \\
\hline & $\mathrm{T}-500$ & 0.012 & 51.9 & 0.8692 & $<0.0001$ \\
\hline \multirow[t]{4}{*}{5} & $\mathrm{~T}-0$ & 0.002 & 73.4 & 0.9858 & $<0.0001$ \\
\hline & $\mathrm{T}-300$ & 0.002 & 75.4 & 0.9814 & $<0.0001$ \\
\hline & $\mathrm{T}-400$ & 0.001 & 84.9 & 0.9826 & $<0.0001$ \\
\hline & $\mathrm{T}-500$ & 0.001 & 104.2 & 0.9778 & $<0.0001$ \\
\hline
\end{tabular}

$\mathrm{T}-0, \mathrm{~T}-300, \mathrm{~T}-400$, and $\mathrm{T}-500$ represent rice rusk and the biochars pyrolysed with temperatures as $300,400,500{ }^{\circ} \mathrm{C}$, respectively. The calculation methods of $r_{\mathrm{adj}}{ }^{2}$ followed $r_{\mathrm{adj}}{ }^{2}=1-$ $\left(1-r^{2}\right)(N-2) /(N-P-2), N$ : the number of experimental data points; $P$ : number of parameters in the model. 
Table 3.

The fitted Weber-Morris intra-particle diffusion model

\begin{tabular}{llllll}
\hline \multirow{2}{*}{$\begin{array}{l}\text { Initial concentration } \\
(\mathrm{mg} / \mathrm{L})\end{array}$} & $\begin{array}{l}\text { pyrolysis } \\
\text { temperatures }\end{array}$ & \multicolumn{4}{l}{ Intra-particle diffusion model } \\
\cline { 3 - 5 } & & $K_{i}$ & $C_{i}$ & $r_{\text {adj }}$ & $P$-value \\
\hline 0.5 & T-0 & 0.688 & 8.097 & 0.8222 & 0.000 \\
& T-300 & 0.834 & 4.139 & 0.8952 & 0.000 \\
\hline
\end{tabular}




\begin{tabular}{cccccc}
\hline & T-400 & 0.901 & 23.64 & 0.6210 & 0.001 \\
T-500 & 0.613 & 44.78 & 0.4279 & 0.009 \\
& T-0 & 3.287 & 25.98 & 0.8497 & 0.000 \\
& T-300 & 3.427 & 28.86 & 0.8514 & 0.000 \\
T-400 & 4.161 & 63.51 & 0.7249 & 0.000 \\
& & & \\
& T-500 & 3.458 & 163.5 & 0.4277 & 0.009 \\
T-0 & 5.848 & 98.21 & 0.8129 & 0.000 \\
T-300 & 6.028 & 89.42 & 0.8159 & 0.000 \\
T-400 & 6.852 & 97.47 & 0.8383 & 0.000 \\
T-500 & 7.958 & 154.3 & 0.7177 & 0.000 \\
\hline
\end{tabular}

T-0, T-300, T-400, and T-500 represent rice rusk and the biochars pyrolysed with temperatures as 300, 400, $500{ }^{\circ} \mathrm{C}$, respectively. The calculation methods of $r_{\mathrm{adj}}{ }^{2}$ followed $r_{\mathrm{adj}}{ }^{2}=1-$ $\left(1-r^{2}\right)(N-2) /(N-P-2), N$ : the number of experimental data points; $P$ : number of parameters in the model. 


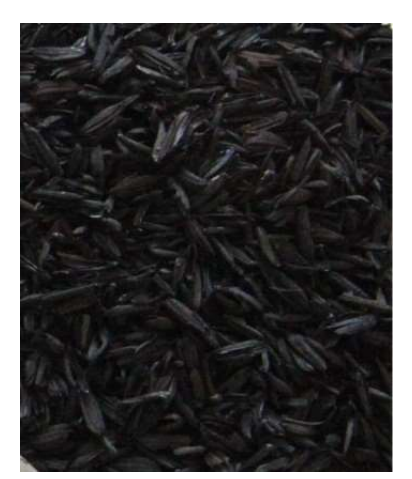

T-300

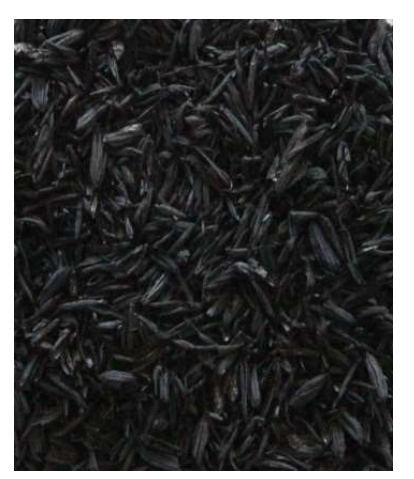

T-400

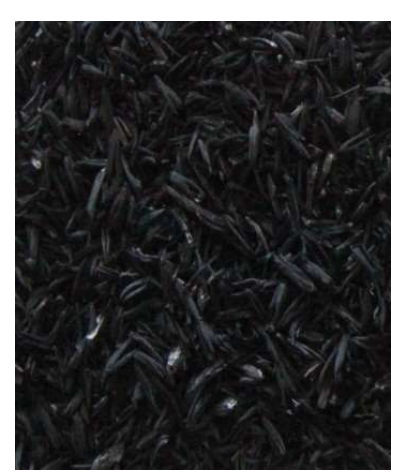

T-500

Fig 1. Biochar produced at pyrolysis temperatures as 300,400 , and $500{ }^{\circ} \mathrm{C}$, respectively. 

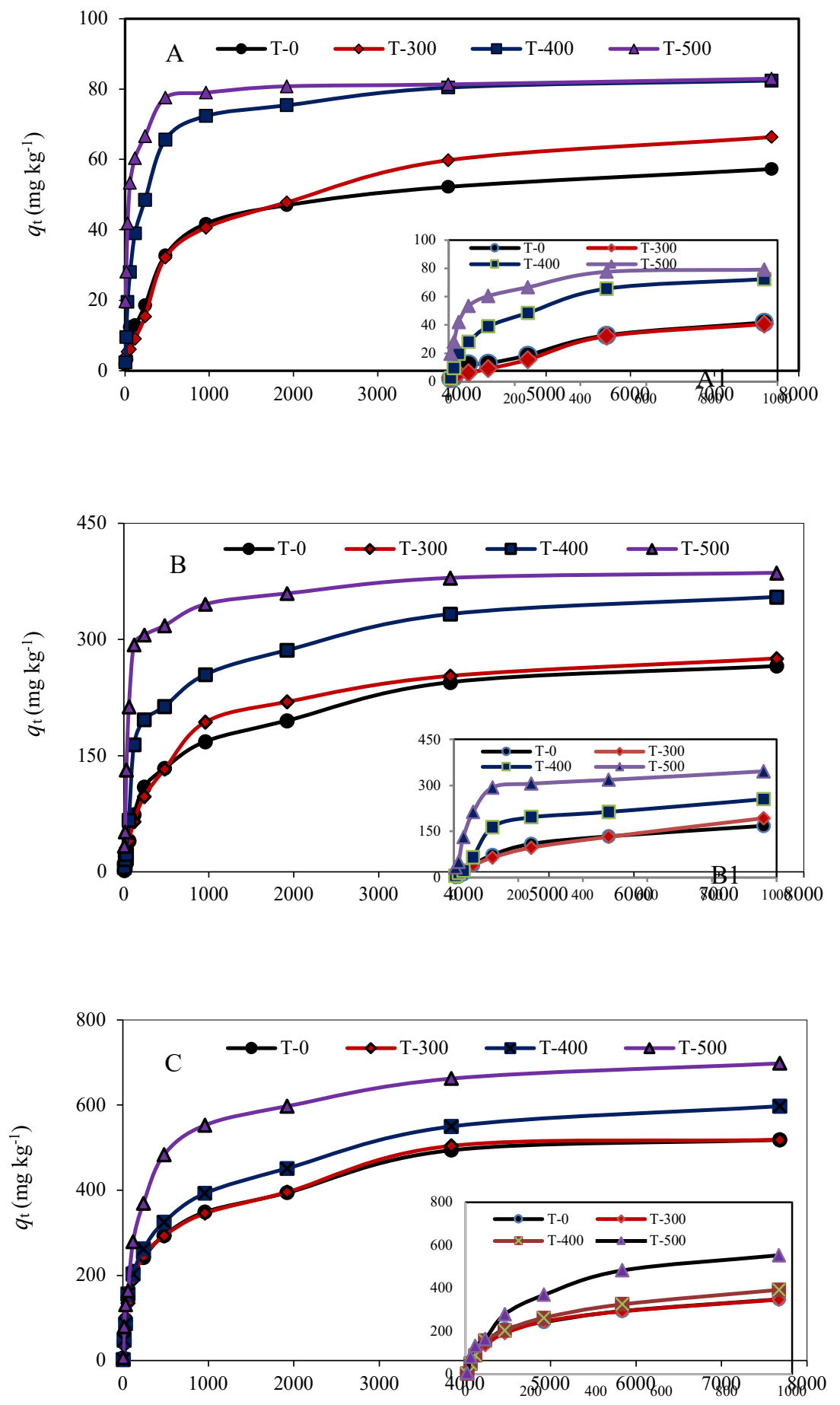
C1

$\mathrm{t}(\min )$

Fig. 2. Adsorption kinetics of $\mathrm{Cd}^{2+}$ on rice rusk (T-0) and biochars with pyrolysis temperatures as 300 (T-300), 400 (T-400), $500{ }^{\circ} \mathrm{C}$ (T-500), respectively. A, B, C represent adsorption kinetics of $\mathrm{Cd}^{2+}$ from beginning to 7680 mins, while $\mathrm{A} 1, \mathrm{~B} 1, \mathrm{C} 1$ represent adsorption kinetics of $\mathrm{Cd}^{2+}$ from beginning to 960 mins with initial concentrations as $0.5,2.5$, and $5 \mathrm{mg} \mathrm{L}^{-1}$, respectively.
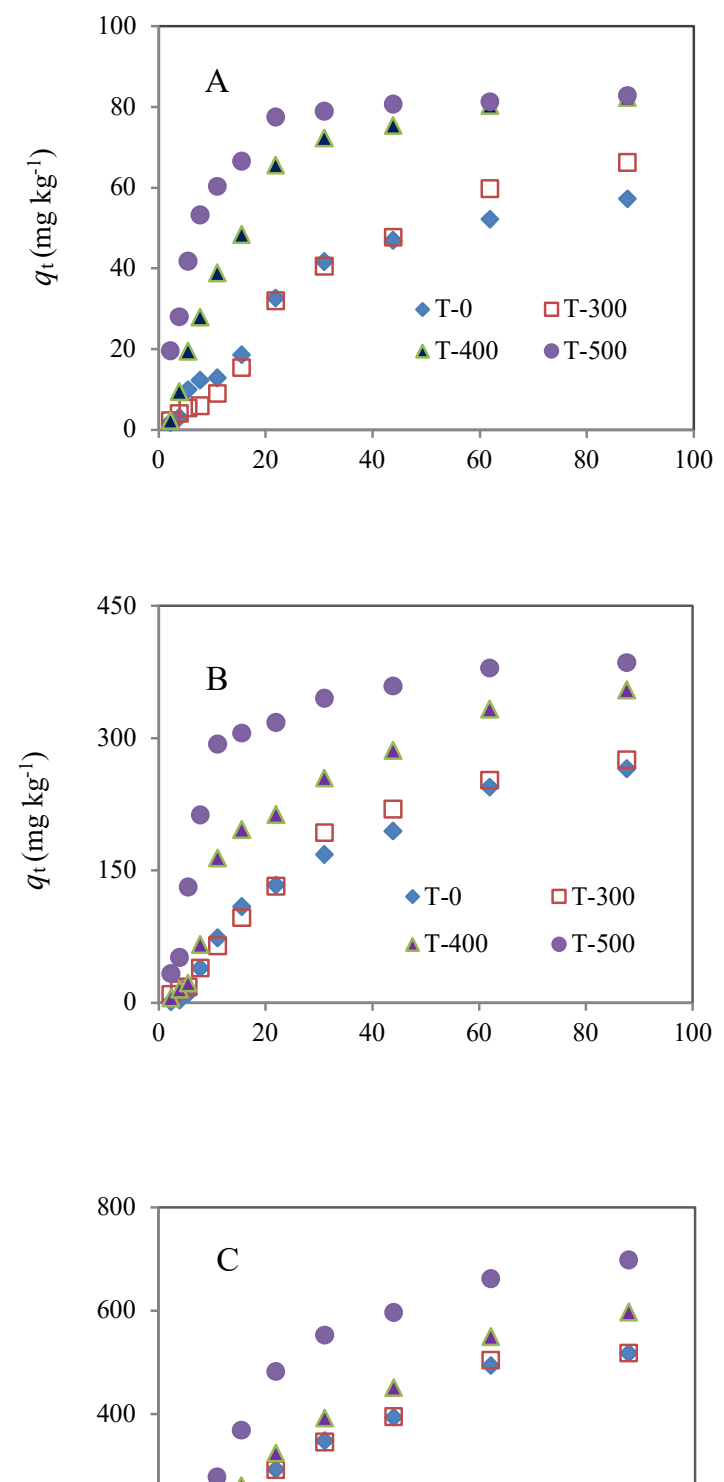


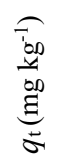

$\mathrm{t}^{0.5}\left(\min ^{0.5}\right)$

Fig. 3. Adsorption kinetics of $\mathrm{Cd}^{2+}$ on rice rusk (T-0) and biochars with pyrolysis temperatures as 300 (T-300), 400 (T-400), $500{ }^{\circ} \mathrm{C}$ (T-500), respectively, depending upon $\mathrm{t}^{0.5}\left(\min ^{0.5}\right)$. A, B, C represent adsorption kinetics of $\mathrm{Cd}^{2+}$ with initial concentrations as $0.5,2.5$, and $5 \mathrm{mg} \mathrm{L}^{-1}$, respectively.

A1

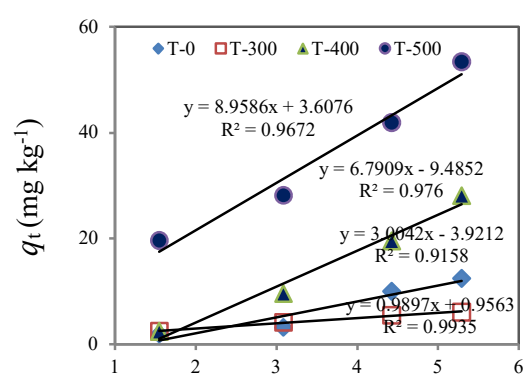

A2

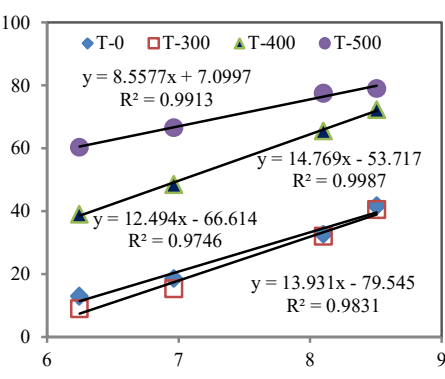

A3

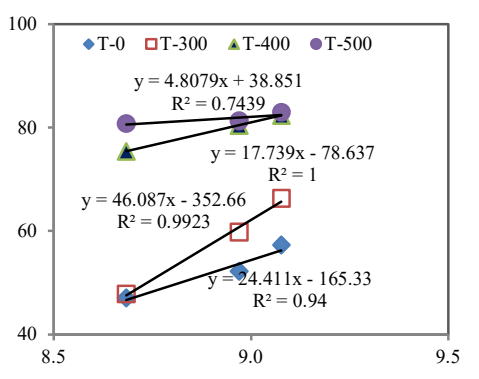

B1

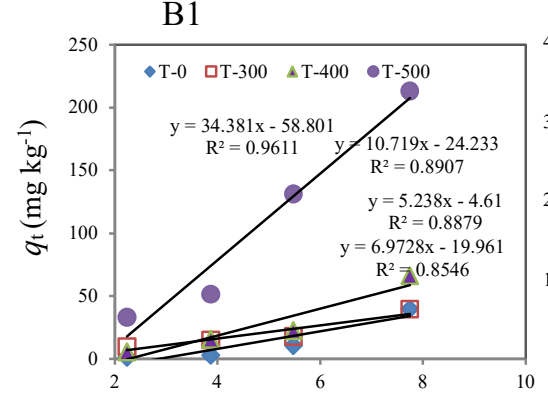

B2

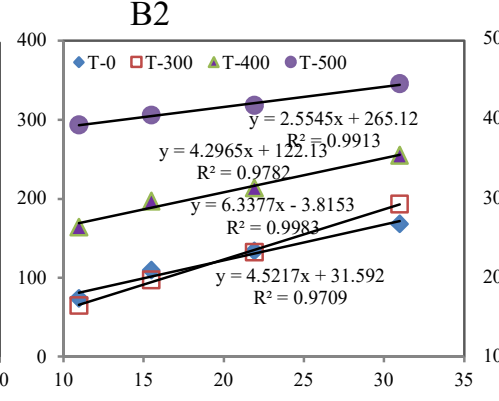

B3

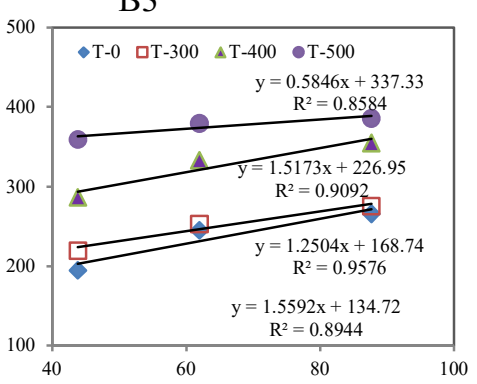


C1

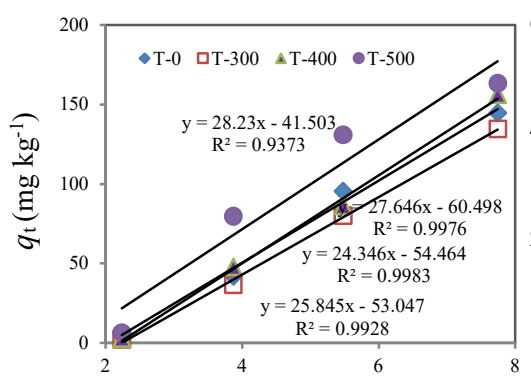

$\mathrm{t}^{0.5}\left(\min ^{0.5}\right)$
$\mathrm{C} 2$

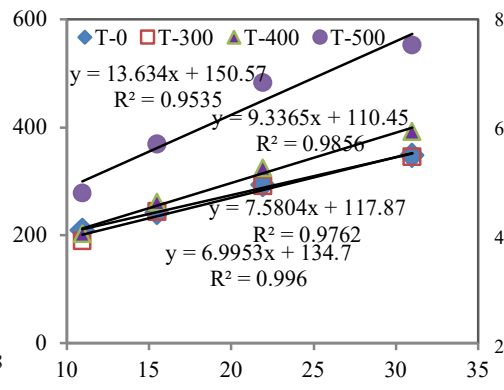

$\mathrm{t}^{0.5}\left(\min ^{0.5}\right)$
C3

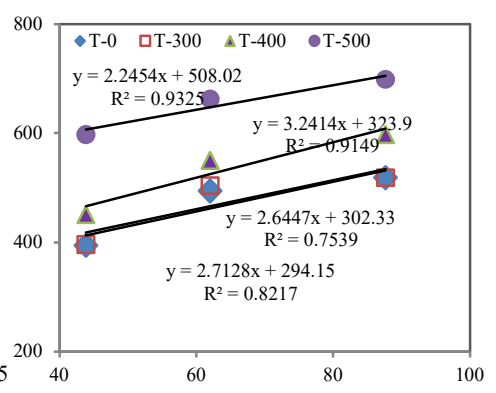

$t^{0.5}\left(\min ^{0.5}\right)$

Fig. 4. Adsorption kinetics of $\mathrm{Cd}^{2+}$ on rice rusk (T-0) and biochars with pyrolysis temperatures as 300 (T-300), 400 (T-400), $500{ }^{\circ} \mathrm{C}$ (T-500), respectively, depending upon $\mathrm{t}^{0.5}\left(\min ^{0.5}\right)$. A, B, C represent adsorption kinetics of $\mathrm{Cd}^{2+}$ with initial concentrations as $0.5,2.5$, and $5 \mathrm{mg} \mathrm{L}^{-1}$, respectively. Correlation analysis between CIP adsorption and $\mathrm{t}^{0.5}\left(\mathrm{~h}^{0.5}\right)$ on the three stages, number 1, 2, and 3 represent stages of external mass transfer, intraparticle diffusion, and adsorption onto the active sites, respectively.
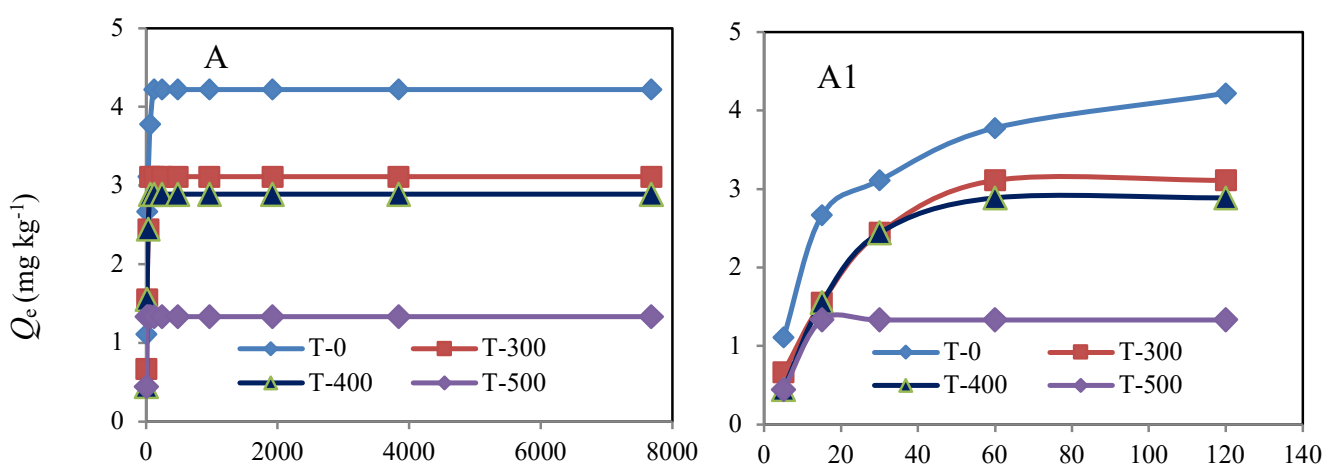

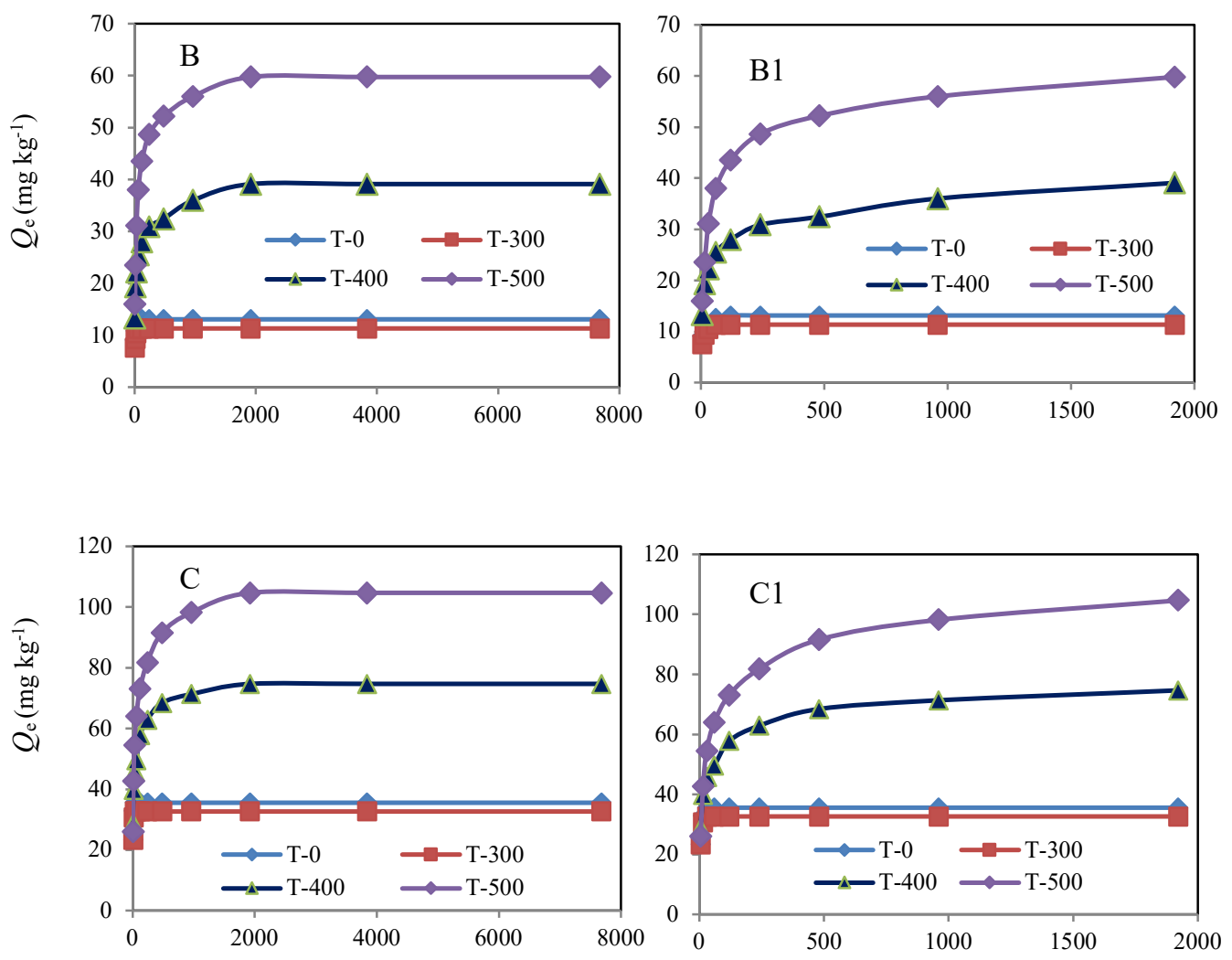

Fig. 5. Desorption kinetics of $\mathrm{Cd}^{2+}$ from rice rusk (T-0) and biochars with pyrolysis temperatures as 300 (T-300), $400(\mathrm{~T}-400), 500{ }^{\circ} \mathrm{C}(\mathrm{T}-500)$, respectively. A, B, C represent desorption of $\mathrm{Cd}^{2+}$ from beginning to 7680 mins, while $\mathrm{A} 1, \mathrm{~B} 1, \mathrm{C} 1$ represent desorption of $\mathrm{Cd}^{2+}$ from beginning to 120 mins for $0.5 \mathrm{mg} \mathrm{L}^{-1}$ initial concentration, and to $1920 \mathrm{mins}$ for 2.5 , and $5 \mathrm{mg} \mathrm{L}^{-1}$, respectively.

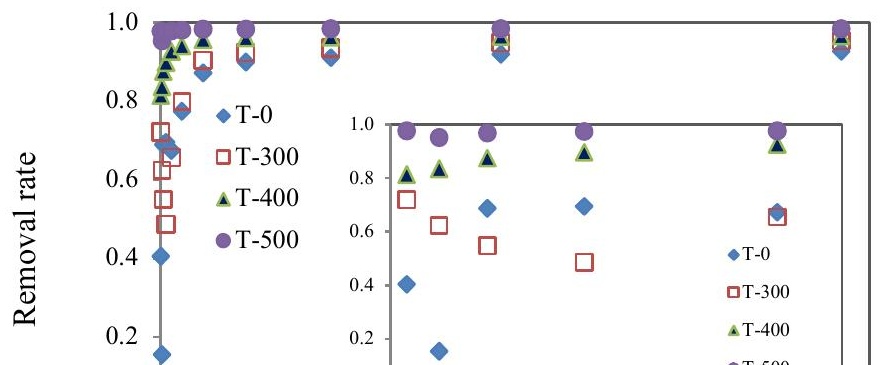


A A1
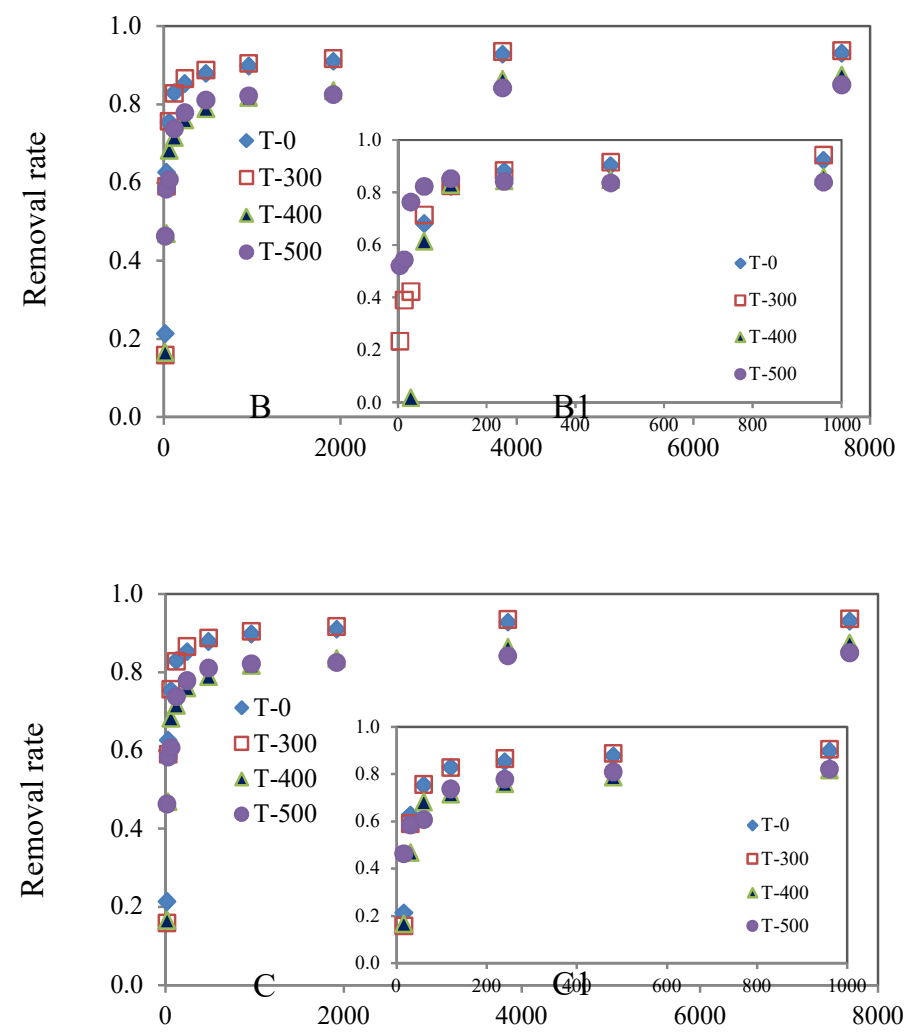

$\mathrm{t}(\min )$

Fig. 6. Removal rate of $\mathrm{Cd}^{2+}$ on rice rusk (T-0) and biochars with pyrolysis temperatures as 300 (T-300), 400 (T-400), $500{ }^{\circ} \mathrm{C}$ (T-500), respectively, from aqueous solution. A, B, C represent removal rate of $\mathrm{Cd}^{2+}$ from beginning to 7680 mins, while $\mathrm{A} 1, \mathrm{~B} 1, \mathrm{C} 1$ represent removal rate of $\mathrm{Cd}^{2+}$ from beginning to 120 mins for $0.5 \mathrm{mg} \mathrm{L}^{-1}$ initial concentration, and to 960 mins with as 2.5 and $5 \mathrm{mg} \mathrm{L}^{-1}$, respectively. 